\title{
Épocas, formas de aplicação e doses de nitrogênio na cultura do milho em condições de cerrado
}

\author{
Maurílio de Sousa Netto ${ }^{1}$, Fernando Castro de Oliveira ${ }^{1}$, Lucas da Silva Araújo ${ }^{1}$, Pedro Marques da Silveira ${ }^{2}$, \\ Paulo César Ribeiro da Cunha ${ }^{1}$ \\ ${ }^{1}$ Instituto Federal Goiano IFG, Urutaí, GO. ${ }^{2}$ Embrapa Arroz e Feijão, Santo Antônio de Goiás, Goiás, Brasil.E-mail: \\ lucasilva31@hotmail.com
}

\section{Resumo}

Objetivou-se avaliar diferentes épocas, formas de aplicação e doses de nitrogênio nas características agronômicas, componentes de produção, produtividade de grãos, bem como a eficiência de utilização do nutriente na cultura do milho. O delineamento experimental de blocos casualizados, em esquema fatorial ( $2 \times 2 \times 4)$ e quatro repetições, foi utilizado para o experimento. Os tratamentos foram duas épocas de aplicação (semeadura do milho e em cobertura no estádio V7); duas formas de aplicação (superficial e incorporada ao solo a $8 \mathrm{~cm}$ de profundidade); e quatro doses de nitrogênio $\left(0,60,120,180 \mathrm{~kg} \mathrm{ha}^{-1}\right.$ ). As características agronômicas do milho, altura da planta, altura da inserção da espiga, diâmetro do colmo e nitrogênio foliar não diferiram em função das épocas ou formas de aplicação, apenas das doses de nitrogênio. Os componentes da produção, comprimento e número de fileiras por espiga, número de grãos por fileira, massa de 100 grãos e produtividade de grãos apresentaram melhores resultados com aplicação do nitrogênio incorporado ao solo e doses de 120 a $180 \mathrm{~kg} \mathrm{ha}^{-1}$ de nitrogênio. A prática de incorporação e a dose de $60 \mathrm{~kg} \mathrm{ha}^{-1}$ propiciaram maior eficiência agronômica no uso do nitrogênio.

Palavras-chave: adubação nitrogenada; ureia; Zea mays L.

Timing, methods of application and doses of nitrogen in corn crop in cerrado conditions.

\begin{abstract}
The objective of this study was to evaluate the different timing, methods of application and nitrogen doses in the agronomic characteristics, production components, grain yield, as well as the nutrient utilization efficiency in the maize crop. The experimental design of randomized blocks, in a factorial scheme $(2 \times 2 \times 4)$ and four replicates, was used for the experiment. The treatments were two application times, (maize sowing and in V7 stage coverage); two forms of application (superficial and incorporated to the soil at $8 \mathrm{~cm}$ depth); and four nitrogen doses $\left(0,60,120,180 \mathrm{~kg} \mathrm{ha}^{-1}\right)$. The agronomic characteristics of corn, plant height, spike insertion height, stalk diameter and leaf nitrogen did not differed according to the seasons or the application forms, only the nitrogen doses. The components of the production, length and number of rows per spike, number of grains per row, mass of 100 grains and grain yield presented better results with application of the nitrogen incorporated in the soil and doses of 120 to $180 \mathrm{~kg} \mathrm{ha}^{-1}$ of nitrogen. The incorporation practice and the $60 \mathrm{~kg} \mathrm{ha}^{-1}$ dose provided greater agronomic efficiency in the use of nitrogen. Keywords: nitrogen fertilization; urea; Zea mays L.
\end{abstract}

\section{Introdução}

O milho em grão se destaca quanto ao volume de produção e área cultivada no Brasil. Entretanto, a produtividade em torno de $5.179 \mathrm{~kg}$ $\mathrm{ha}^{-1}$, observadas nas últimas dez safras não condiz com potencial da cultura (CONAB, 2020).
Um dos fatores recorrentes que contribui para o baixo nível produtivo do milho, refere-se ao fornecimento insuficiente de nitrogênio (N), contrapondo-se ao emprego acentuado de fertilizantes nitrogenados na agricultura (HIREL et al., 2011). 
Os mecanismos de perdas por volatilização de amônia $\left(\mathrm{NH}_{3}{ }^{+}\right)$, desnitrificação $\left(\mathrm{N}_{2}\right)$, lixiviação do nitrato $\left(\mathrm{NO}_{3}{ }^{-}\right)$e erosão do solo são apontados como causas na redução da eficiência da adubação nitrogenada (CANTARELLA, 2007). A volatilização de amônia constitui o principal fator responsável por perdas de $\mathrm{N}$, sendo mais expressivas quando utilizada a ureia (BOUWMEESTER et al., 1985).

No milho, a adubação nitrogenada na forma de ureia representa quase a totalidade do consumo com fertilizantes nitrogenados (FRAZÃO et al., 2014). A preferência do agricultor pelo fertilizante é explicada pela alta concentração de $\mathrm{N}$ e no menor custo por unidade do nutriente (CIVARDI et al., 2011). Contudo, as perdas de $\mathrm{N}$ por volatilização de amônia, após a aplicação da ureia podem ser significativas nas lavouras de milho.

Civardi et al. (2011) reportaram perdas por volatilização de amônia de $30 \%$ com a aplicação da ureia na superfície do solo em sistema de preparo convencional. Em condições similares, Lara Cabezas et al. (1997) constataram perdas de $\mathrm{N}-\mathrm{NH}_{3}{ }^{+}$de $31 \%$, com reflexos negativos a produtividade de milho, diminuída em $11,8 \mathrm{~kg}$ ha ${ }^{1}$ de grãos para cada quilograma de $\mathrm{N}$ volatilizado.

Devido ao grande potencial de perdas na forma de ureia, existe o interesse em minimizar o processo de volatilização e, por conseguinte elevar a eficácia da fertilização nitrogenada. Dentre as alternativas para se reduzirem as perdas de N, destacam-se as formas de aplicação, épocas $e$ doses que influenciam no aproveitamento do nutriente pelas plantas de milho.

Há evidências de que a incorporação da ureia em relação à aplicação superficial consiste na melhor estratégia para minimizar as perdas de $\mathrm{N}$ por volatilização (SANGOI et al., 2003). Enquanto, os resultados sobre a melhor época de aplicação tem sido inconsistentes, mostrando ser eficaz a aplicação total de $\mathrm{N}$ na semeadura de forma incorporada ao solo (CASAGRANDE; FORNASIERI FILHO 2002), ao passo que outros estudos demonstram que deve ser mantida a aplicação de $\mathrm{N}$ em cobertura (MEIRA et al., 2009; ANDRADE et al., 2014). Em relação às doses de $N$, os maiores incrementos na produção de grãos de milho têm sido obtidos com doses elevadas, que normalmente ultrapassam $100 \mathrm{~kg} \mathrm{ha}^{-1}$ (ANDRADE et al., 2014; FRAZÃO et al., 2014; OLIVEIRA et al., 2016).
Portanto, este trabalho foi realizado considerando a hipótese de que a eficiência agronômica da ureia depende, principalmente, das práticas agrícolas, referentes ao manejo da adubação nitrogenada. Por isto, objetivou-se comparar diferentes épocas, formas de aplicação e doses de nitrogênio nas características agronômicas, componentes de produção, produtividade de grãos, bem como a eficiência de utilização do nutriente na cultura do milho cultivada em Latossolo Vermelho Distrófico do Cerrado.

\section{Materiais e métodos}

O experimento de campo foi conduzido em sequeiro durante os meses de 11/12 a 04/2013 na área experimental do Instituto Federal Goiano, localizado no município de Urutaí, Goiás, com milho híbrido comercial P30F53YH ${ }^{\circ}$. O experimento foi implantado em altitude de aproximadamente $800 \mathrm{~m}$, latitude 48 11' 35" S e longitude 48 11' 35" W.

O clima da região possui inverno seco e verão chuvoso Aw Köppen (ALVARES et al., 2014). Foram registrados os dados de precipitação e temperatura média no decorrer do experimento (Figura 1). O solo da área experimental é um Latossolo Vermelho Distrófico de textura argilosa, com $\mathrm{pH}\left(\mathrm{CaCl}_{2}\right)=5,1 ; \mathrm{M} . \mathrm{O}$. $=25 \mathrm{~g} \mathrm{dm}^{-3} ; \mathrm{Ca}^{+2}$, $\mathrm{Mg}^{+2}, \mathrm{~K}^{+}$e $\mathrm{Al}^{+3}=1,9,0,8,0,28$ e $0,1 \mathrm{cmol}_{\mathrm{c}} \mathrm{dm}^{-3}$, respectivamente; $P=3,4 \mathrm{mg} \mathrm{dm}^{-3}$ e $V=53 \%$, na camada de 0 a $20 \mathrm{~cm}$.

Figura 1. Precipitação e temperatura média durante o período de novembro de 2012 a abril de 2013. Urutaí, Goiás, 2013. Fonte: Instituto Nacional de Meteorologia - INMET (2020).

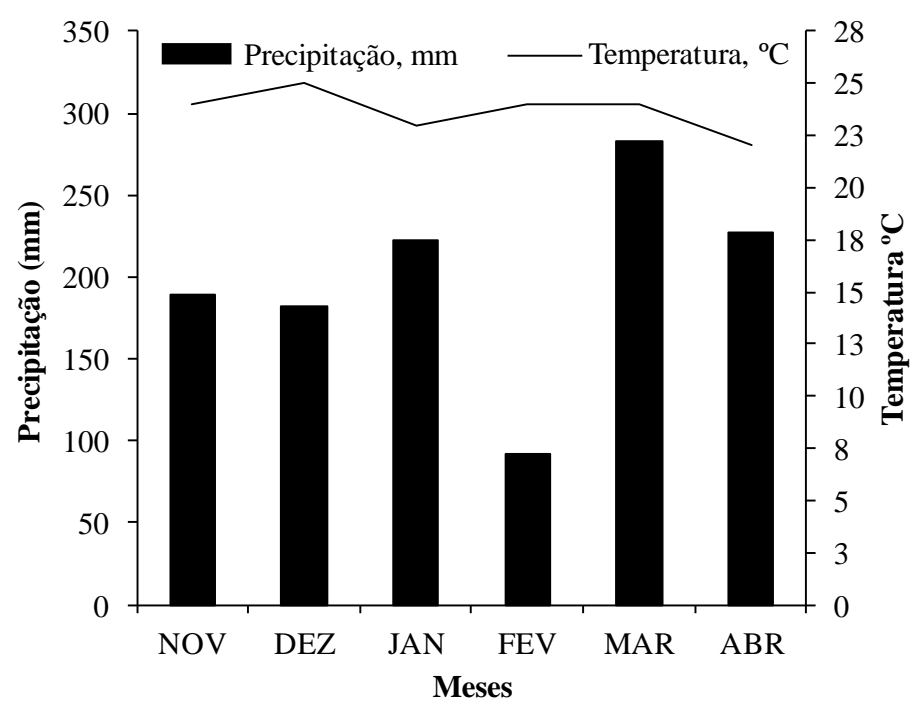


O delineamento experimental de blocos casualizados, em esquema fatorial $(2 \times 2 \times 4)$ e quatro repetições, foi utilizado para 0 experimento. Os tratamentos foram duas épocas de aplicação (semeadura do milho e em cobertura no estádio V7); duas formas de aplicação (superficial e incorporada ao solo a 8 $\mathrm{cm}$ de profundidade); e quatro doses de nitrogênio $\left(0,60,120,180 \mathrm{~kg} \mathrm{ha}^{-1}\right)$. Usou-se como fonte de $\mathrm{N}$ a ureia ( $45 \%$ de $\mathrm{N}$ ). As parcelas tinham $3 \mathrm{~m}$ de largura e $6 \mathrm{~m}$ de comprimento, perfazendo área total de $18 \mathrm{~m}^{2}$. As duas fileiras centrais, desprezando $1 \mathrm{~m}$ de cada extremidade foram utilizadas com área útil, totalizando $4 \mathrm{~m}^{2}$.

A área foi preparada de forma convencional, pois o solo encontrava-se compactado, impossibilitando a semeadura direta. Para esse preparo foi realizada uma subsolagem, seguida de uma gradagem na profundidade de $\pm 0,25 \mathrm{~m}$ e duas gradagens superficiais para o destorroamento do solo. Posteriormente, a semeadura manual ocorreu em $20 / 11 / 2012$. Para isso, foram abertos sulcos de plantio por meio de sulcador de haste de seis linhas, com tração mecanizada. Adotou-se o espaçamento de $0,50 \mathrm{~m}$ entre as fileiras de milho, e uma população inicial de 70.000 plantas por hectare ( 3,5 sementes por metro). Com base na análise de solo e expectativa de produção, a adubação de base consistiu na aplicação manual de $60 \mathrm{~kg} \mathrm{ha}^{-1}$ de $\mathrm{K}_{2} \mathrm{O}$ e 120 e kg ha ${ }^{-1}$ de $\mathrm{P}_{2} \mathrm{O}_{5}$. $\mathrm{O}$ adubo foi colocado na profundidade de $8 \mathrm{~cm}$ e as sementes depositadas de forma equidistante a 5 $\mathrm{cm}$ de profundidade sem contato direto com $\mathrm{o}$ adubo.

Em relação à adubação nitrogenada, a ureia foi incorporada no sulco de plantio com os demais fertilizantes no momento da semeadura, ao passo que a aplicação superficial foi distribuída homogeneamente ao lado das linhas de semeadura, aproximadamente $10 \mathrm{~cm}$. No estádio fenológico V7 (sete folhas completamente expandidas) realizou-se a adubação de cobertura em 20/12/2012 (30 dias após a semeadura), sendo a ureia aplicada na superfície do solo ou incorporada a $8 \mathrm{~cm}$ de profundidade, a uma distância de $10 \mathrm{~cm}$ das fileiras das plantas.

No estádio fenológico V4 (quatro folhas completamente expandidas) foi realizado 0 controle químico das plantas daninhas em pósemergência, aplicando-se a mistura de atrazina (1500 $\mathrm{g} \mathrm{ha}^{-1}$ ) e nicosulfuron (30 $\mathrm{g} \mathrm{ha}^{-1}$ ). Para insetos-pragas e doenças foliares, não foram constatados níveis de danos econômicos que justificassem aplicações de inseticidas e fungicidas.

Por ocasião do florescimento feminino, início do embonecamento, o terço central de três folhas opostas e abaixo da primeira espiga foi amostrado em dez plantas por parcela, totalizando 30 folhas (MARTINEZ et al., 1999). Após a secagem em estufa de circulação forçada de ar, a $60 \pm 5$ 으, as folhas foram moídas em moinho tipo Wiley, sendo determinado o teor de $\mathrm{N}$, segundo Malavolta et al. (1997). No campo, avaliou-se em pré-colheita, a altura da planta e inserção da espiga principal, medida com uma trena graduada em centímetros desde a superfície do solo até a inserção da última folha e até a base da espiga, respectivamente. O diâmetro do colmo foi determinado a $5 \mathrm{~cm}$ da superfície do solo com um paquímetro digital. Estas análises foram realizadas em dez plantas aleatórias por parcela.

A colheita foi manual e realizada em 22/04/2013, portanto152 dias após a semeadura. $\mathrm{Na}$ ocasião, foram escolhidas aleatoriamente dez espigas, que após despalhadas, determinou-se o comprimento com auxílio de uma régua graduada em centímetros e o número de fileiras de grãos e grãos por fileira mediante contagem. Em seguida as espigas foram debulhadas por meio de um debulhador manual. Assim, determinou-se a massa de 100 grãos pela média de quatro amostras. A produtividade de grãos foi determinada por meio da pesagem de todos os grãos advindos da área útil de cada parcela experimental e posteriormente, calculou-se a produtividade em $\mathrm{kg} \mathrm{ha}^{-1}$. Os resultados de massa e produtividade de grãos foram corrigidos para o conteúdo de água de $13 \%$, utilizando-se de um medidor portátil do conteúdo de água nos grãos, Gehaka modelo G800.

Determinou-se a eficiência agronômica (EA): produção econômica obtida (grãos, no caso de culturas anuais) por unidade de nutriente aplicado, a partir da equação abaixo:

$$
\mathrm{EA}=\frac{(\mathrm{PGca}-\mathrm{PGsa})}{\mathrm{QNa}}
$$

Em que: EA é a eficiência agronômica, em $\mathrm{kg} \mathrm{kg}^{-1}$; PGca é a produção, em kg, com adubação; PGsa é a produção, em $\mathrm{kg}$, sem adubação; QNa é a quantidade de nutriente aplicado, em $\mathrm{kg}$.

Os dados foram submetidos à análise de variância (ANOVA) e quando detectado efeito significativo do teste $F(p<0,05)$, as médias das épocas e formas de aplicação (tratamentos 
qualitativos) foram comparados pelo teste de Tukey $(p<0,05)$, enquanto as médias das doses de $\mathrm{N}$ foram analisadas mediante a análise de regressão. Todas as análises estatísticas foram realizadas no software $R^{\circ}$ (R CORE TEAM, 2017).

\section{Resultados e discussão}

No manejo da adubação nitrogenada, as características agronômicas, altura da planta, altura da inserção da espiga, diâmetro do colmo e nitrogênio foliar, foram influenciadas apenas pelas doses de $\mathrm{N}$, independente da época ou forma de aplicação (Tabela 1). Não houve interação para qualquer característica agronômica e nitrogênio foliar nas plantas de milho.

Tabela 1. Características agronômicas (altura da planta, altura da inserção da espiga, diâmetro do colmo) e nitrogênio foliar em função das épocas, formas de aplicação e doses de nitrogênio no milho. Urutaí, Goiás, 2013.

\begin{tabular}{|c|c|c|c|c|}
\hline \multirow[t]{2}{*}{ Tratamentos } & $\begin{array}{c}\text { Altura da } \\
\text { planta }\end{array}$ & $\begin{array}{c}\text { Altura da } \\
\text { espiga }\end{array}$ & $\begin{array}{c}\text { Diâmetro do } \\
\text { colmo }\end{array}$ & Nitrogênio foliar \\
\hline & $\mathrm{m}$ & $\mathrm{m}$ & $\mathrm{mm}$ & $\mathrm{g} \mathrm{kg}^{-1}$ \\
\hline \multicolumn{5}{|c|}{ Época de aplicação - E } \\
\hline Semeadura & 2,13 & 1,17 & 23,31 & 24,89 \\
\hline Cobertura & 2,09 & 1,13 & 22,87 & 23,20 \\
\hline Teste $\mathrm{F}$ & $2,03^{\text {ns }}$ & $2,95^{\mathrm{ns}}$ & $2,12^{\text {ns }}$ & $3,82^{\text {ns }}$ \\
\hline \multicolumn{5}{|c|}{ Forma de aplicação - F } \\
\hline Superficial & 2,11 & 1,15 & 22,92 & 24,20 \\
\hline Incorporado & 2,12 & 1,14 & 23,27 & 23,87 \\
\hline Teste F & $0,08^{\text {ns }}$ & $0,05^{\text {ns }}$ & $1,35^{\mathrm{ns}}$ & $0,13^{\text {ns }}$ \\
\hline \multicolumn{5}{|c|}{ Dose de $N\left(\mathrm{~kg} \mathrm{ha}^{-1}\right)-\mathrm{D}$} \\
\hline 0 & 2,00 & 1,06 & 19,74 & 17,12 \\
\hline 60 & 2,14 & 1,19 & 22,57 & 25,72 \\
\hline 120 & 2,15 & 1,16 & 24,48 & 26,77 \\
\hline 180 & 2,16 & 1,18 & 25,58 & 26,56 \\
\hline Teste $\mathrm{F}$ & $6,78^{* *}$ & $5,95^{* *}$ & $70,80^{* *}$ & $28,79^{* *}$ \\
\hline$E \times F$ & $1,22^{\text {ns }}$ & $2,23^{\text {ns }}$ & $0,19^{\text {ns }}$ & $0,01^{\text {ns }}$ \\
\hline$E \times D$ & $0,38^{\text {ns }}$ & $0,39^{\text {ns }}$ & $0,29^{\text {ns }}$ & $0,55^{\mathrm{ns}}$ \\
\hline$F \times D$ & $0,28^{\mathrm{ns}}$ & $0,56^{\text {ns }}$ & $0,23^{\mathrm{ns}}$ & $0,47^{\text {ns }}$ \\
\hline$E \times F \times D$ & $0,70^{\text {ns }}$ & $1,00^{\mathrm{ns}}$ & $0,29^{\text {ns }}$ & $0,37^{\text {ns }}$ \\
\hline CV (\%) & 5,20 & 8,75 & 5,26 & 14,37 \\
\hline
\end{tabular}

${ }^{\mathrm{Ns}}$ Não significativo. ${ }^{* *}$ Significativo a $\mathrm{p}<0,01$ de probabilidade pelo teste F. CV: Coeficiente de variação.

A ausência de resposta das características agronômicas e o teor foliar de $\mathrm{N}$ as práticas agrícolas (épocas e formas de aplicação de N), em parte, podem estar relacionadas ao teor inicial de matéria orgânica ( $25 \mathrm{~g} \mathrm{~kg}^{-1}$ ou $50 \mathrm{~kg}_{\text {de }} \mathrm{N} \mathrm{ha}^{-1}$ ) presente no solo. Portanto, é possível que, com o seu revolvimento pelas operações de preparo da área, a incorporação da matéria orgânica tenha provocado sua mineralização, com consequente suprimento de $\mathrm{N}$ à cultura na fase inicial de desenvolvimento.

Em outros estudos, solos com teores não limitantes de matéria orgânica $\left(>25 \mathrm{~g} \mathrm{~kg}^{-1}\right), a$ época de aplicação de $\mathrm{N}$ também não influenciou o diâmetro de colmo (MEIRA et al., 2009;
ZUCARELI et al., 2014), entretanto quando o teor era baixo $\left(15 \mathrm{~g} \mathrm{~kg}^{-1}\right)$ foi constatado colmos finos nas plantas que receberam todo $\mathrm{N}$ na semeadura (ANDRADE et al., 2014).Outro ponto importante, as características altura da planta e altura da inserção da espiga são fortemente dependentes do genótipo de milho (ANDRADE et al., 2014; ZUCARELI et al. 2014), portanto diminui as chances de efeito pelas épocas e formas de aplicação.

$\mathrm{O}$ teor de $\mathrm{N}$ foliar confirma que as épocas e formas de aplicação proporcionaram as plantas condições semelhantes de aproveitamento do N, considerando os níveis satisfatórios de matéria orgânica e condições favoráveis de chuvas (Figura 
1). Esses resultados concordam com os de Casagrande e Fornasieri Filho (2002) e Mar et al. (2003) que não encontraram diferenças entre as épocas de aplicação. Entretanto, em alguns casos, foram verificadas alterações no teor foliar de $\mathrm{N}$ (MEIRA et al., 2009; ANDRADE et al., 2014). Destaca-se nestes estudos, que independente da época de aplicação, as plantas que receberam aplicação da ureia superficialmente apresentaram menor teor de $\mathrm{N}$ nas folhas.

Embora não tenha havido diferença para as formas e épocas de aplicação, a altura da planta e inserção da espiga, apesar de pouco dependente do ambiente, foram influenciadas pelas doses de $\mathrm{N}$, assim como o diâmetro do colmo e o teor foliar de $\mathrm{N}$ (Figura 2)

Figura 2. Características agronômicas e nitrogênio foliar em razão de doses de nitrogênio no milho. Urutaí, Goiás, 2013. ${ }^{*} \mathrm{e}^{* *}$ Significativo a $\mathrm{p}<0,05$ e $\mathrm{p}<0,01$ de probabilidade, respectivamente.
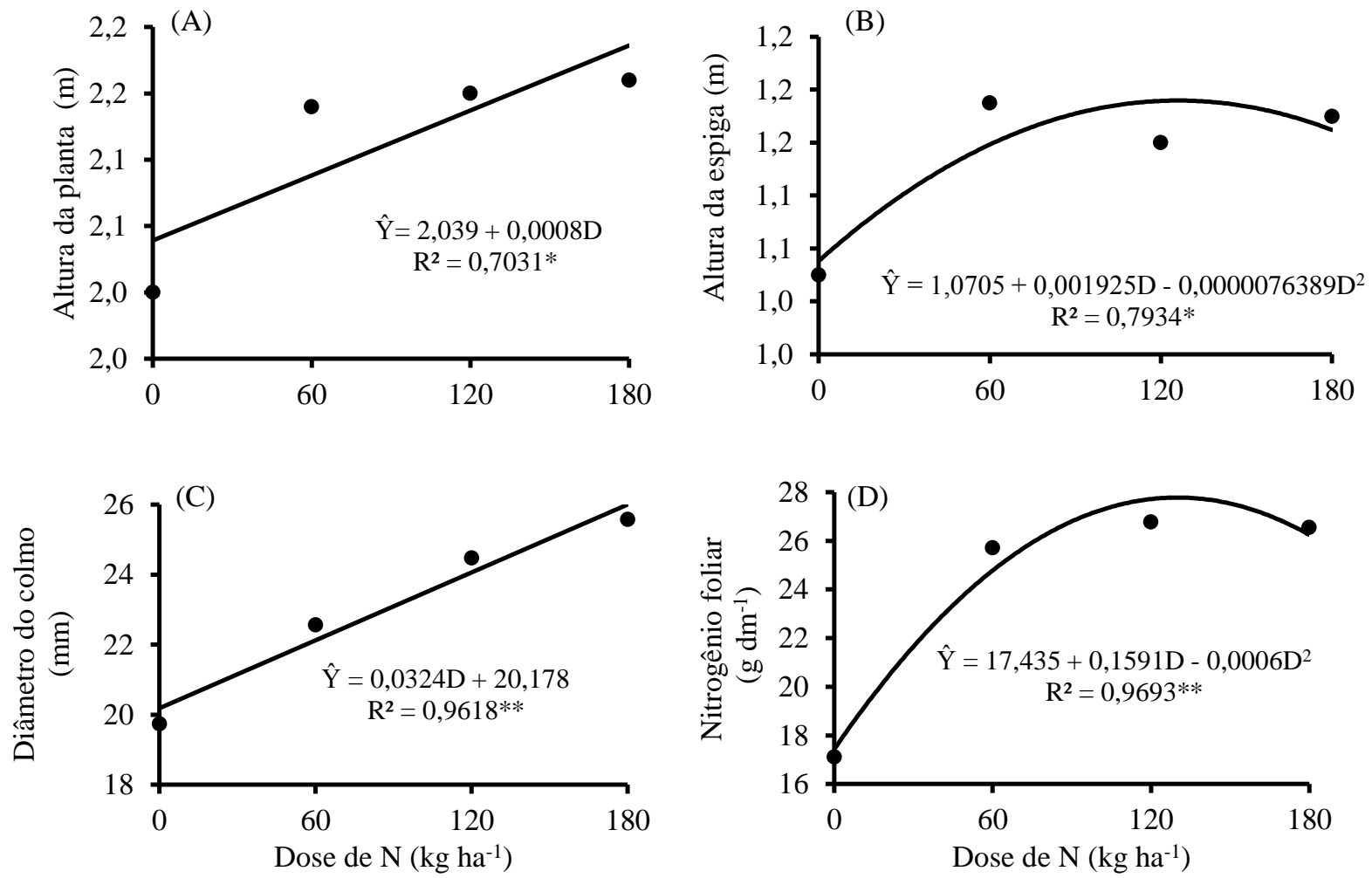

Para a altura de plantas e diâmetro do colmo, as doses se comportaram de forma linear (Figura 2A e 2C), enquanto efeito quadrático foi verificado na altura da inserção da espiga e teor foliar de $\mathrm{N}$ (Figura 2B e 2D). As plantas não conseguiram atingir a máxima altura da planta e diâmetro do colmo até a dose de $180 \mathrm{~kg} \mathrm{ha}^{-1}$ de N. Em média, as plantas adubadas com $180 \mathrm{~kg}$ ha 1 de $\mathrm{N}$ tiveram aumento de 7,4 e $22,8 \%$, respectivamente, quando comparado, às médias das plantas sem adubação nitrogenada. Diferentemente, para máxima altura da inserção da espiga e teor foliar de $\mathrm{N}$, estimou-se a dose máxima de 125,9 e $132,6 \mathrm{~kg} \mathrm{ha}^{-1}$ de $\mathrm{N}$, as quais propiciaram aumento de 10,9 e $38,81 \%$, respectivamente, em relação à média das plantas que não receberam $\mathrm{N}$.

Os resultados obtidos neste trabalho evidenciam que as características agronômicas e teor foliar de $\mathrm{N}$ são influenciados pela adubação nitrogenada, principalmente pelas doses de $\mathrm{N}$, pois na ausência delas, as plantas apresentaramse com menor altura, colmos finos e menor teor foliar de $\mathrm{N}$. Estes resultados confirmam a colocação de Mello et al. (2017), de que o N está diretamente envolvido na divisão e expansão celular e no processo fotossintético. Logo, isso explica a importância do $\mathrm{N}$ no crescimento vegetativo e na nutrição adequada das plantas de milho.

Respostas positivas das doses de $\mathrm{N}$ sobre altura da planta e altura da inserção da espiga foram reportadas na literatura (DUETE et al., 2008; ANDRADE et al., 2014; OLIVEIRA et al., 2016). De modo geral, os resultados apontam 
pouco efeito das doses sobre crescimento em altura à medida que se eleva a quantidade de $\mathrm{N}$ aplicado. De fato, estas características são dependentes também da genética dos materiais de milho, por isso pode colaborar em parte, a não resposta às doses de $\mathrm{N}$, como observado em outros estudos (CASAGRANDE; FORNASIERI FILHO, 2002).

Os resultados deste estudo foram expressivos para o diâmetro do colmo em função do aumento das doses de $\mathrm{N}$ e condizem com os observados por outros autores (SORATTO et al., 2010, ANDRADE et al., 2014; OLIVEIRA et al., 2016). Normalmente, atribui-se colmos grossos a maior capacidade de reserva de nutrientes, que potencialmente pode contribuir para 0 enchimento de grãos. De fato, a produtividade de grãos do milho correlacionou-se positivamente com o diâmetro de colmo (SORATTO et al., 2010) e, portanto, plantas de colmos grossos são preferidas, pois além de suportarem mais ao acamamento, são capazes de atingir maiores produtividades.

O nível de concentração de $\mathrm{N}$ foliar aumentou com a aplicação de maiores doses de $\mathrm{N}$ (Figura 2) e essa resposta positiva em outros estudos (SORATTO et al., 2010; ANDRADE et al., 2014; OLIVEIRA et al., 2016) confirmam o teor de $\mathrm{N}$ foliar responsivo à adubação nitrogenada. Apesar disso, mesmo com incremento no teor de $\mathrm{N}$ foliar, os valores não foram considerados adequados à cultura do milho, por estar abaixo do intervalo ótimo de $\mathrm{N}$ de 27 a $35 \mathrm{~g} \mathrm{~kg}^{-1}$ de matéria seca (MALAVOLTA, 2006).

Nenhum dos componentes da produção e produtividade de grãos foram influenciados pela época de aplicação, enquanto as formas de aplicação afetaram significativamente, exceto para o número de fileiras por espiga, e os componentes da produção e produtividade de grãos foram influenciados pelas doses de $\mathrm{N}$ (Tabela

Tabela 2. Componentes da produção, comprimento da espiga (CE), número de fileiras por espiga (NFE), número de grãos por fileira (NGF), massa de 100 grãos (M100), produtividade de grãos (PG) e eficiência agronômica (EA) em razão das épocas, formas de aplicação e doses de nitrogênio no milho. Urutaí, Goiás, 2013.

\begin{tabular}{|c|c|c|c|c|c|c|}
\hline Tratamento & $\begin{array}{l}\mathrm{CE} \\
\mathrm{cm}\end{array}$ & $\begin{array}{l}\text { NFE } \\
\mathrm{n}^{\circ}\end{array}$ & $\begin{array}{l}\text { NGF } \\
\mathrm{n}^{\circ} \\
\end{array}$ & $\begin{array}{c}\text { M100 } \\
\text { g }\end{array}$ & $\begin{array}{c}\text { PG } \\
\mathrm{kg} \mathrm{ha}^{-1}\end{array}$ & $\begin{array}{c}\mathrm{EA} \\
\left(\mathrm{kg} \mathrm{kg}^{-1}\right)\end{array}$ \\
\hline \multicolumn{7}{|c|}{ Época de aplicação - E } \\
\hline Semeadura & 15,71 & 16,72 & 35,98 & 32,30 & 9604 & 47,36 \\
\hline Cobertura & 15,80 & 16,69 & 36,51 & 32,78 & 9571 & 44,38 \\
\hline Teste $\mathrm{F}$ & $0,32^{\mathrm{ns}}$ & $0,03^{\text {ns }}$ & $1,17^{\text {ns }}$ & $1,62^{\text {ns }}$ & $0,03^{\mathrm{ns}}$ & $1,62^{\text {ns }}$ \\
\hline \multicolumn{7}{|c|}{$\begin{array}{l}\text { Formas de aplicação - } \\
\text { F }\end{array}$} \\
\hline Superficial & $15,47 \mathrm{~b}$ & 16,75 & $35,47 b$ & $31,98 \mathrm{~b}$ & $9386 \mathrm{~b}$ & $41,28 b$ \\
\hline Incorporado & $16,04 \mathrm{a}$ & 16,66 & $37,03 \mathrm{a}$ & $33,11 \mathrm{a}$ & 9789 a & $50,45 \mathrm{a}$ \\
\hline Teste $\mathrm{F}$ & $12,96^{* *}$ & $1,42^{\text {ns }}$ & $10,27^{* *}$ & $6,87^{*}$ & $4,81^{*}$ & $15,21^{* *}$ \\
\hline \multicolumn{7}{|c|}{ Dose de $N\left(\mathrm{~kg} \mathrm{ha}^{-1}\right)$ - D } \\
\hline 0 & 12,30 & 16,20 & 28,05 & 27,41 & 5884 & - \\
\hline 60 & 15,03 & 16,71 & 34,70 & 31,99 & 9166 & $54,7 \mathrm{a}$ \\
\hline 120 & 17,29 & 16,86 & 39,91 & 34,52 & 11084 & $43,3 \mathrm{~b}$ \\
\hline 180 & 18,39 & 17,05 & 42,33 & 36,24 & 12218 & $39,6 \mathrm{~b}$ \\
\hline Teste $\mathrm{F}$ & $281,66^{* *}$ & $8,41^{* *}$ & $483,93^{* *}$ & $80,00^{* *}$ & $227,56^{* *}$ & $14,98^{* *}$ \\
\hline$E \times F$ & $0,36^{\text {ns }}$ & $0,48^{\text {ns }}$ & $0,34^{\mathrm{ns}}$ & $1,39^{\text {ns }}$ & $0,88^{\mathrm{ns}}$ & $0,03^{\text {ns }}$ \\
\hline$E \times D$ & $0,28^{\mathrm{ns}}$ & $1,09^{\text {ns }}$ & $0,01^{\mathrm{ns}}$ & $1,72^{\text {ns }}$ & $0,25^{n s}$ & $1,71^{\mathrm{ns}}$ \\
\hline$F \times D$ & $2,35^{\mathrm{ns}}$ & $0,29^{\text {ns }}$ & $1,17^{\mathrm{ns}}$ & $0,25^{\mathrm{ns}}$ & $0,86^{\mathrm{ns}}$ & $0,68^{\text {ns }}$ \\
\hline$E \times F \times D$ & $0,48^{\text {ns }}$ & $0,95^{\mathrm{ns}}$ & $0,01^{\text {ns }}$ & $1,26^{\mathrm{ns}}$ & $0,74^{\mathrm{ns}}$ & $4,53^{* *}$ \\
\hline CV (\%) & 4,08 & 3,01 & 5,38 & 5,28 & 7,67 & 17,75 \\
\hline
\end{tabular}

\footnotetext{
${ }^{~ N s}$ Não significativo. ", , Significativo a $p<0,01$ e $p<0,05$, respectivamente pelo teste $F$. Médias na coluna seguidas pela
} mesma letra não diferem entre si pelo teste de Tukey $p<0,05$. CV: Coeficiente de variação. 
Em outros estudos, a época de aplicação de $\mathrm{N}$ também não influenciou o comprimento da espiga, número de fileiras por espiga, número de grãos por fileira e massa de grãos (CASAGRANDE; FORNASIERI FILHO, 2002; MEIRA et al., 2009; ANDRADE et al., 2014; ZUCARELI et al., 2014). Os resultados confirmam que os efeitos da época de aplicação de $\mathrm{N}$ são pouco pronunciados no que se refere aos componentes da produção do milho.

Para a produtividade de grãos, a aplicação de todo $\mathrm{N}$ na semeadura não diferiu da aplicação em cobertura no estádio V7 (Tabela 2), corroborando com os resultados obtidos por Casagrande e Fornasieri Filho (2002), Andrade et al. (2014) e Zucareli et al. (2014). Entretanto, em outros trabalhos, inclusive em sistemas convencionais do preparo do solo, a aplicação de todo $\mathrm{N}$ na semeadura ocasionou decréscimos na produtividade e, portanto, a antecipação de $\mathrm{N}$ não deve ser generalizada para todos as situações (Mar et al., 2003; Meira et al., 2009).

Os componentes da produção (comprimento da espiga, número de grãos por fileira e massa de 100 grãos) e produtividade de grãos apresentaram os maiores valores quando a ureia foi incorporada ao solo (Tabela 2). Assim, plantas que receberam $\mathrm{N}$ incorporado produziram espigas com comprimento superior as espigas produzidas por plantas adubadas com $\mathrm{N}$ sem incorporação. Para o número de grãos por fileira, massa de 100 grãos e produtividade de grãos, houve aumento considerados quando se incorpora a ureia. Isto confirma que a aplicação da ureia incorporada ao solo melhora a eficiência da adubação nitrogenada, provavelmente por reduzir às perdas de $\mathrm{N}$ por volatilização de amônia, por conseguinte, há maior aproveitamento de $\mathrm{N}$ pelo milho e maior resposta dos componentes da produção e produtividade de grãos.

A ureia incorporada ao solo propiciou o maior comprimento médio de espigas, número de grãos por espiga, massa de 100 grãos e, em consequência, a maior produtividade de grãos (CIVARDI et al., 2011). Portanto, os resultados comprovam que a incorporação de $\mathrm{N}$ ocasiona aumentos significativos nos componentes da produção e produtividade do milho.

A respeito das doses de $\mathrm{N}$, houve incremento linear para o comprimento da espiga, número de fileiras por espiga, número de grãos por fileira, massa de grãos e produtividade de grãos, logo, a dose de $180 \mathrm{~kg} \mathrm{ha}^{-1}$ de $\mathrm{N}$ não foi suficiente para promover a máxima expressão dos componentes da produção e produtividade do milho (Figura 3) 
Figura 3. Componentes da produção e produtividade de grãos em razão de doses de nitrogênio no milho. Urutaí, Goiás, 2013. * e ${ }^{* *}$ Significativo a $p<0,05$ e $p<0,01$ de probabilidade, respectivamente.
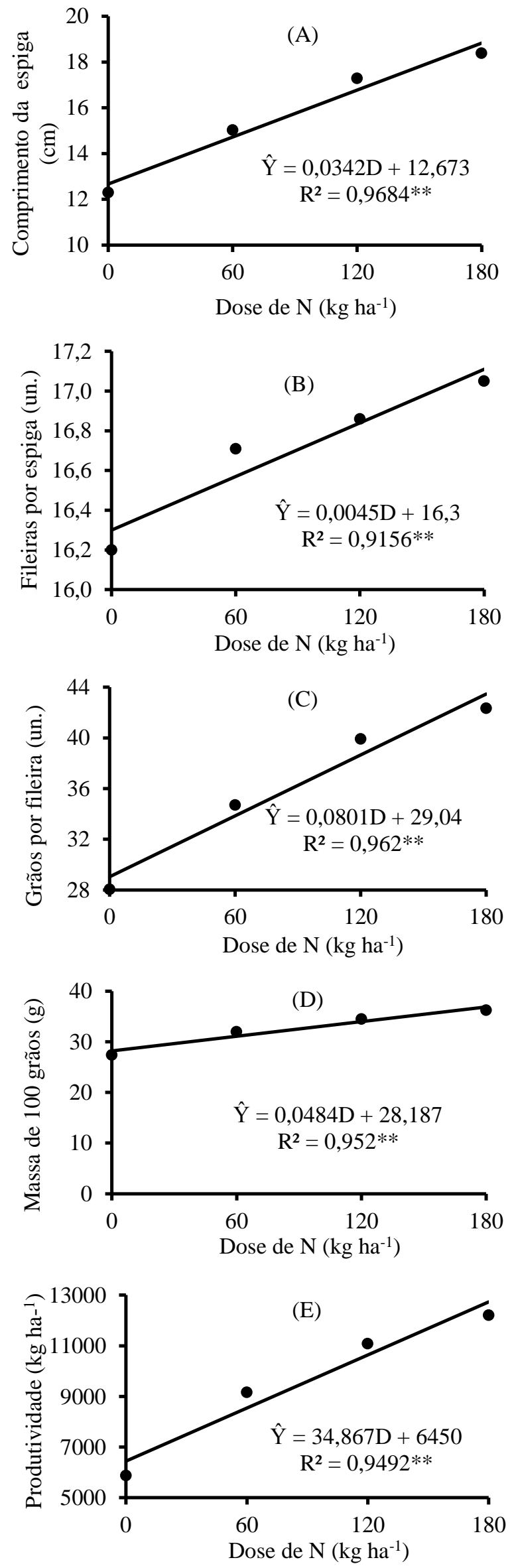
As espigas de maior comprimento receberam $180 \mathrm{~kg} \mathrm{ha}^{-1}$ de $\mathrm{N}$, isso correspondeu ao aumento de $33,1 \%$ quando comparado às espigas produzidas por plantas que não receberam $\mathrm{N}$ (Figura $3 \mathrm{~A}$ ). Para o número de fileiras por espiga, número de grãos por fileira e massa de 100 grãos observou-se aumento de 4,9 , 33,7 e $24,4 \%$, respectivamente quando a dose foi de $180 \mathrm{~kg} \mathrm{ha}^{-1}$ de $\mathrm{N}$ em comparação com as plantas que não foram adubadas com $\mathrm{N}$ (Figura 3B, 3C e 3D). A produtividade de grãos de 12.218 $\mathrm{kg} \mathrm{ha}^{-1}$ utilizando a dose de $180 \mathrm{~kg} \mathrm{ha}^{-1}$ de $\mathrm{N}$ foi o dobro da produtividade alcançada pelas plantas que não receberam adubação nitrogenada que foi de $5.884 \mathrm{~kg} \mathrm{ha}^{-1}$ (Figura 3E).

Os acréscimos verificados para os componentes da produção e produtividade de grãos revelam o papel fundamental do $\mathrm{N}$ na predição do tamanho da espiga, número de fileiras por espigas, número de grãos por fileira, massa de grãos, principalmente, na produtividade do milho. Portanto, doses elevadas de $\mathrm{N}$ favorecem o melhor desenvolvimento da espiga, no que se refere a maior quantidade de grãos, enchimento e aumento da massa de grãos.
Em outros estudos (DUETE et al., 2008; SORATTO et al., 2010; ANDRADE et al., 2014; OLIVEIRA et al., 2016), os melhores resultados de componentes da produção e produtividade de grãos foram obtidos com doses a partir de $100 \mathrm{~kg}$ $\mathrm{ha}^{-1}$ de $\mathrm{N}$, encontradas por modelos lineares ou quadráticos de regressão.

Em relação à eficiência agronômica (EA), o desdobramento da interação entre as épocas e formas de aplicação e dose de $\mathrm{N}$, aponta que apenas quando $\mathrm{N}$ foi incorporado ao solo, houve efeito da época de aplicação (Tabela 3). Deste modo, quando aplicado $60 \mathrm{~kg} \mathrm{ha}{ }^{-1}$ de $\mathrm{N}$, constatou-se a maior eficiência do uso do $\mathrm{N}$ aplicado em cobertura no estádio V7 $(66,6 \mathrm{~kg} \mathrm{~kg}$ ${ }^{1}$ ), entretanto o inverso foi observado quando se aumentou a dose para $180 \mathrm{~kg} \mathrm{ha}^{-1} \mathrm{de} \mathrm{N}$, em que a época de aplicação na semeadura do milho propiciou maior eficiência do uso do $\mathrm{N}(52,6 \mathrm{~kg}$ $\mathrm{kg}^{-1}$ ). Para forma de aplicação de $\mathrm{N}$, a maior EA foi observada quando o $\mathrm{N}$ foi incorporado ao solo, tanto na dose de $180 \mathrm{~kg} \mathrm{ha}^{-1}$ aplicada no momento da semeadura $\left(52,6 \mathrm{~kg} \mathrm{~kg}^{-1}\right)$ quanto na dose de $60 \mathrm{~kg} \mathrm{ha}^{-1}$ aplicada na época de cobertura $\left(66,6 \mathrm{~kg} \mathrm{~kg}^{-1}\right)$.

Tabela 3. Eficiência agronômica do uso de nitrogênio (N) em razão das épocas, formas de aplicação e doses de nitrogênio no milho. Urutaí, Goiás, 2013.

\begin{tabular}{ccccccc}
\hline \multirow{2}{*}{$\begin{array}{c}\text { Época de } \\
\text { aplicação }\end{array}$} & \multicolumn{3}{c}{ Doses de N $\left(\mathrm{kg} \mathrm{ha}^{-1}\right)$} \\
\cline { 2 - 6 } & Superficial & Incorporado & Superficial & Incorporado & Superficial & Incorporado \\
\hline Semeadura & $52,6 \mathrm{Aa} \alpha$ & $54,8 \mathrm{Ab} \alpha$ & $41,3 \mathrm{ABa} \alpha$ & $47,9 \mathrm{Aa} \alpha$ & $35,1 \mathrm{Ba} \beta$ & $52,6 \mathrm{Aa \alpha}$ \\
Cobertura & $44,9 \mathrm{Aa} \beta$ & $66,6 \mathrm{Aa \alpha}$ & $40,0 \mathrm{Aa} \alpha$ & $44,2 \mathrm{Ba} \alpha$ & $33,9 \mathrm{Aa} \alpha$ & $36,7 \mathrm{Bb} \alpha$ \\
\hline
\end{tabular}

Letras minúsculas iguais na coluna não diferem significativamente pelo teste de Tukey, a $p<0,05$, assim como letras maiúsculas iguais na linha em cada dose de $\mathrm{N}$ e época de aplicação e gregas na linha em cada forma de aplicação.

Com relação às doses de $\mathrm{N}$, quando a adubação nitrogenada foi antecipada para semeadura, à medida que se aumentou a quantidade de $\mathrm{N}$ aplicada na superfície do solo, a eficiência no uso de $\mathrm{N}$ apresentou decréscimos significativos, resultado contrário ao observado para o $\mathrm{N}$ incorporado ao solo, que manteve a mesma EA. Já para época, a dose de $\mathrm{N}$ não influenciou a EA quando aplicado na superfície, enquanto para aplicação do $\mathrm{N}$ incorporado, $\mathrm{O}$ aumento das doses de $\mathrm{N}$ também proporcionou a redução da eficiência do uso de N. Os resultados do presente estudo corroboram com os obtidos por Andrade et al. (2014), que também encontraram maior eficiência agronômica do uso de $\mathrm{N}$ com emprego da menor dose do nutriente.
De modo geral, o efeito da época de aplicação de $\mathrm{N}$ foi pouco pronunciado na eficiência agronômica do uso de $\mathrm{N}$ e a aplicação de $\mathrm{N}$ incorporado ao solo propiciou à melhor produção de grãos por unidade de $\mathrm{N}$ aplicado. Além disso, a maior eficiência agronômica no uso do $\mathrm{N}$ foi verificada com a aplicação de dose de 60 $\mathrm{kg} \mathrm{ha}^{-1}$ de $\mathrm{N}$, indicando que a dose aplicada que proporcionou maior produtividade (180 kg ha ${ }^{-1}$ ) não foi à dose que proporcionou a maior eficiência agronômica.

\section{Conclusões}

As características agronômicas do milho, altura da planta, altura da inserção da espiga, diâmetro do colmo e nitrogênio foliar não 
diferenciaram em função das épocas ou formas de aplicação, apenas das doses de nitrogênio.

Os componentes da produção, comprimento e número de fileiras por espiga, número de grãos por fileira, massa de 100 grãos e produtividade de grãos apresentaram melhores resultados com aplicação do nitrogênio incorporado ao solo e doses de 120 a $180 \mathrm{~kg} \mathrm{ha}^{-1}$ de nitrogênio, independentemente da época de aplicação.

A prática de incorporação e a dose de $60 \mathrm{~kg}$ $\mathrm{ha}^{-1}$ na época de cobertura propiciaram maior eficiência agronômica no uso do nitrogênio.

\section{Referências}

ALVARES, C. A.; STAPE, J. L.; SENTELHAS, P. C.; MORAES GONÇALVES, J. L.; SPAROVEK, G. Köppen's climate classification map for Brazil. Meteorologische Zeitschrift, v. 22, n. 6, p.711728, 2014. https://doi.org/10.1127/0941$\underline{2948 / 2013 / 0507}$

ANDRADE, F. R.; PETTER, F. A.; NÓBREGA, J. C. A.; PACHECO, L. P.; ZUFFO, A. M. Desempenho agronômico do milho a doses e épocas de aplicação de nitrogênio no Cerrado piauiense. Amazonian Journal of Agricultural and Environmental Sciences, v. 57, n. 4, p.358-366, 2014. http://dx.doi.org/10.4322/rca.1295

BOUWMEESTER, R. J. B.; VLEK, P. L. G.; STUMPE, J. M. Effect of environmental factors on ammonia volatilization from a urea-fertilizer soil. Soil Science Society of America Journal, v. 49, n. 2, p.376-381, 1985. http://dx.doi.org/10.2136/sssaj1985.0361599500 4900020021x

CANTARELLA, H. Nitrogênio. In: NOVAIS, R. F.; VENEGAS, V. H. A.; BARROS, N. F.; FONTES, R. L. F.; CANTARUTTI, R. B.; NEVES, J. C. L. Fertilidade do solo. Viçosa: Sociedade Brasileira de Ciência do Solo, 2007. p. 375-470.

CASAGRANDE, J. R. R.; FORNESIERI FILHO, D. Adubação nitrogenada na cultura do milho safrinha. Pesquisa Agropecuária Brasileira, v. 37, n. $1, \quad$ p.33-40, 2002. http://dx.doi.org/10.1590/S0100$\underline{204 X 2002000100005}$

CIVARDI, E. A.; NETO, A. N. S.; RAGAGNIN, V. A.; GODOY, E. R.; BROD, E. Ureia de liberação lenta aplicada superficialmente e ureia comum incorporada ao solo no rendimento do milho. Pesquisa Agropecuária Tropical, v. 41, n. 1, p.5259, 2011. http://dx.doi.org/10.5216/pat.v41i1.8146

CONAB. Série histórica das safras. 2018. Disponível em: http://www.conab.gov.br/conteudos.php?a=125 $\underline{2 \& \mathrm{t}}=$. Acesso em: 28 out. 2020.

DUETE, R. R. C.; MURAOKA, T.; SILVA, E. C.; TRIVELIN, P. C. O.; AMBROSANO, E. J. Manejo da adubação nitrogenada e utilização do nitrogênio $\left({ }^{15} \mathrm{~N}\right)$ pelo milho em Latossolo Vermelho. Revista Brasileira de Ciência do Solo, v. 32, n. 1, p.161171, 2008. http://dx.doi.org/10.4025/actasciagron.v31i1.664 $\underline{6}$

FRAZÃO, J. J.; SILVA; Á. R.; SILVA, V. L.; OLIVEIRA, V. A.; CORRÊA, R. S. Fertilizantes nitrogenados de eficiência aumentada e ureia na cultura do milho. Revista Brasileira de Engenharia Agrícola e Ambiental, v. 18, n. 12, p.1262-1267, 2014. http://dx.doi.org/10.1590/18071929/agriambi.v18n12p1262-1267

HIREL, B.: TÉTU, T.; LEA, P. J.; DUBOIS, F. Improving Nitrogen Use Efficiency in Crops for Sustainable Agriculture. Sustainability, v. 3, n. 9, p.1452-1485, 2011. http://dx.doi.org/10.3390/su3091452

INMET. Precipitação e temperatura média. 2020. Disponível em: http://www.inmet.gov.br/portal/.index.php?r=bdm ep/bdmep. Acesso em: 28 out. 2020.

LARA CABEZAS, W. A. R.; KORNDORFER, G. H.; MOTTA, S. A. Volatilização de $\mathrm{N}-\mathrm{NH}_{3}$ na cultura de milho: II. Avaliação de fontes sólidas e fluidas em sistema de plantio direto e convencional. Revista Brasileira de Ciência do Solo, v. 21, n. 3, p.489496, 1997. http://dx.doi.org/10.1590/S0100$\underline{06831997000300019}$

MALAVOLTA, E. Manual de nutrição mineral de plantas. Piracicaba: Editora Ceres, 2006.

MALAVOLTA, E.; VITTI, G. C.; OLIVEIRA, S. A. Avaliação do estado nutricional das plantas. 2. ed. Piracicaba: Associação Brasileira para Pesquisa da Potassa e do Fosfato, 1997. 
MAR, G. D.; MARCHETTI; M. E.; SOUZA, L. C. F.; GONÇALVES; M. C.; NOVELINO, J. O. Produção do milho safrinha em função de doses e épocas de aplicação de nitrogênio. Bragantia, v. 62 , n. 2, p.267-274, 2003. http://dx.doi.org/10.1590/S0006$\underline{87052003000200012}$

MARTINEZ, H. E. P.; CARVALHO, J. G.; SOUZA, R. B. Diagnose foliar. In: RIBEIRO, A. C.; GUIMARÃES, P. T. G.; ALVAREZ, V. H. Recomendações para o uso de corretivos e fertilizantes em Minas Gerais: 5a aproximação. Viçosa: Comissão de Fertilidade do Solo do Estado de Minas Gerais, 1999. p.143-168.

MEIRA, F. A.; BUZETTI; S.; ANDREOTTI, M.; ARF, O.; SÁ, M. E.; ANDRADE, J. A. C. Fontes e épocas de aplicação do nitrogênio na cultura do milho irrigado. Semina: Ciências Agrárias, v. 30, n. 2, p.275-284, 2009. http://dx.doi.org/10.5433/1679$\underline{0359.2009 v 30 n 2 p 275}$

MELLO, T. F. BUZETTI, S.; FILHO, M. C. M. T.; GALINDO, F. S.; NOGUEIRA, L. M. Residual effects of nitrogen fertilizer with polymer-coated urea in a corn crop. Revista Caatinga, v. 30, n.3, p.586594, 2017. http://dx.doi.org/10.1590/198321252017v30n306rc

OLIVEIRA, F. C.; NETTO, M. S.; ARAÚJO, L. S.; ALMEIDA, A. C. S.; SILVEIRA, P. M.; CUNHA, P. C. R. Corn development and production in function of sources of nitrogen fertilizers and doses. Revista Caatinga, v. 29, n. 4, p.812-821, 2016. http://dx.doi.org/10.1590/1983-

21252016v29n405rc

R ORE TEAM. R: a language and environment for statistical computing. 2017. Disponível em: http://www.R-project.org/. Acesso em: 21 mar. 2018.

SANGOI, L.; ERNANI, P. R.; LECH, V. A.; RAMPAZZO, C. Volatilização de N-NH3 em decorrência da forma de aplicação de ureia, manejo de resíduos e tipo de solo, em laboratório. Ciência Rural, v. 33, n. 4, p.687-692, $2003 . \quad$ http://dx.doi.org/10.1590/S0103$\underline{84782003000400016}$

SORATTO, R. P.; PEREIRA, M.; COSTA, T. A. M.; LAMPERT, V. N. Fontes Alternativas e doses de nitrogênio no milho safrinha em sucessão à soja. Revista Ciência Agronômica, v. 41, n. 4, p.511518, 2010. http://dx.doi.org/10.1590/S1806$\underline{66902010000400002}$

ZUCARELI, C.; ALVES, G. B.; OLIVEIRA, M. A.; MACHADO, M. H. Desempenho agronômico do milho safrinha em resposta às épocas de aplicações e fontes de nitrogênio. Científica, v.4 2, n. 1, p.60-67, 2014. http://dx.doi.org/10.15361/19845529.2014v42n1p60-67 